Irving, M.A.; Corrêa, F.V.; Conti, B.R.; Botelho, E.S.; Peixoto, S.L. Corcovado: reflexões sobre imaginários e impressões dos turistas no Parque Nacional da Tijuca (RJ) no contexto de valorização da cidade pela UNESCO. Revista Brasileira de Ecoturismo, São Paulo, v.5, n.3, set/dez-2012, pp.464-481.

\title{
Corcovado: reflexões sobre imaginários e impressões dos turistas no Parque Nacional da Tijuca $(R J)$ no contexto de valorização da cidade pela UNESCO
}

\author{
Corcovado: Reflections about imaginaries and impressions of tourists in the \\ National Park of Tijuca (RJ, Brazil) in the context of the city upgrade by UNESCO
}

\section{Marta de Azevedo Irving, Frances Vivian Corrêa, Bruna Ranção Conti, Eloise Silveira Botelho, Sônia Lúcia Peixoto}

\section{RESUMO}

O Corcovado, um dos símbolos mais significativos do Rio de Janeiro, situado no Parque Nacional da Tijuca, representa um ícone do processo de reconhecimento da cidade como "Paisagem Cultural da Humanidade" pela UNESCO. E ilustra como poucos atrativos da cidade, a indissociabilidade entre natureza e cultura, principalmente no momento em que se rediscute as estratégias de planejamento ecoturístico, na perspectiva de parques nacionais no Brasil. Tendo em vista o valor simbólico do Corcovado neste debate e, a importância crescente da cidade para o turismo nacional e internacional, o objetivo deste trabalho é contribuir para interpretar como se expressa o imaginário e as impressões dos turistas que ali chegam, na perspectiva do debate sobre natureza e cultura. O trabalho se desenvolveu com base em pesquisa bibliográfica e documental, complementada com dados de campo. Esta pesquisa, embora exploratória e preliminar, ilustra, pedagogicamente, o sentido do título de "Paisagem Cultural da Humanidade" atribuído ao Rio de Janeiro pela UNESCO.

PALAVRAS-CHAVE: Corcovado; Imaginários; Turistas; Parque Nacional da Tijuca; UNESCO.

\section{ABSTRACT}

The Corcovado, one of the most important monuments and symbol of Rio de Janeiro, situated in the National Park of Tijuca, represents one icon in the process of recognition of the city as "Cultural Landscape of Humanity" by UNESCO. And this illustrates, as few attractions of the city, the link between nature and culture, especially in the moment of the rediscussion of the strategies of ecoturism in planning for national parks, in Brazil. Considering the symbolic value of Corcovado in this debate and, the growing importance of the city for the national and international tourism, the objective of this paper is to contribute to interpret how the imaginaries and impressions of the tourists are expressed, in the perspective of the debate connected to the relation between nature and culture. The work was developed based on documental and bibliographic research, complemented by data from field research. This paper although a preliminary approach to this complex theme, illustrates, pedagogically, the meaning of the title "Cultural, Landscape of Humanity" attributed to Rio de Janeiro by UNESCO.

KEYWORDS: Corcovado; Imaginaries; Tourists; National Park of Tijuca; UNESCO. 


\title{
Introdução e objetivos da pesquisa
}

A cidade do Rio de Janeiro acaba de ser reconhecida como "Paisagem Cultural da Humanidade" pela UNESCO (Organização das Nações Unidas para a Educação, a Ciência e a Cultura ${ }^{1}$, o que reafirma o seu potencial turístico na expressão mais evidente da relação natureza e cultura, em uma área urbana complexa, construída e resignificada pelo modo de vida local e pelas identidades que, historicamente, compõem o sentido de paisagem.

No processo da UNESCO de afirmação de bens de valor global, o Rio de Janeiro foi a primeira cidade reconhecida como paisagem cultural urbana, por materializar a sinergia pulsante envolvida na indissociabilidade entre natureza e cultura, o que se traduz, no imaginário sobre a cidade, em uma nova perspectiva, que transcende o lugar comum dos cartões postais e impõe às políticas públicas uma nova maneira de interpretar o turismo não apenas como atividade de mercado mas também como fenômeno social complexo.

Anteriormente a decisão da UNESCO, Almeida e Lodi (2012) já tinham discutido esta temática argumentando sobre as especificidades da cidade e seu potencial para se transformar em um possível patrimônio mundial e da importância desse título para a sua preservação, no futuro. Para eles, a cidade possui uma das mais complexas paisagens culturais no plano global, integrando uma rica diversidade cultural e sítios naturais excepcionais, o que imprime um sentido de originalidade à paisagem urbana. Para os autores:

\begin{abstract}
O valor universal excepcional do Rio é fruto da sensibilidade da ação do homem ao se deparar com uma natureza absolutamente singular e estonteante, que o estimulou a construir de forma deliberada, determinada, onde a relação homem-cidade-natureza mantém-se equilibrada e reconhecida como um monumento à qualidade de vida e ao prazer de viver em uma urbe (ALMEIDA; LODI, 2012, p.81).
\end{abstract}

Vale mencionar como ponto de partida para este argumento que, para Gagnon (2005), a noção de paisagem traduz, em si mesma, a resultante da inter-relação entre homem e natureza. Neste sentido, pode ser entendida como a "intermediação entre o físico e o fenômeno, entre a ecologia e o simbólico, entre o factual e o sensível" (BERQUE, 1995).

Esta afirmação parece também importante para ilustrar, uma vez mais, a interpretação que a cidade do Rio de Janeiro inspira aos turistas que ali chegam não apenas a partir da impressão de uma natureza exuberante e complexa mas o sentido de um lugar que se constrói e se reconfigura, permanentemente, em função do modo de vida local, das influências culturais históricas e do sentido cosmopolita de processo inacabado, conforme discutido por Irving, Corrêa e Moraes(2011).

Não se pode ignorar, neste contexto, o papel do Rio de Janeiro como "vitrine" 
do país, principalmente a partir da década de 1980, com o movimento de valorização e investimento nacional no turismo, incrementado, mais recentemente, pelos Planos Nacionais de Turismo de 2003-2007 e 2007-2010. Nesse contexto, uma das principais portas de entrada do turista estrangeiro no Brasil, a cidade do Rio de Janeiro, adquire um status ainda mais significativo em planejamento turístico, como sede de importantes eventos mundiais como a "Rio + 20", evento da ONU sobre Desenvolvimento Sustentável, em junho de 2012, a final da Copa do Mundo, em 2014 e, os Jogos Olímpicos em 2016, apenas para citar os mais importantes.

Mas não se pode esquecer que no plano de reconhecimento do Rio de Janeiro como "Paisagem Cultural da Humanidade" e seu impacto global, alguns ícones permanecem como elementos simbólicos associados à sua identidade no imaginário global e à expressão da indissociabilidade entre natureza e cultura, entre eles, o Pão de Açúcar, o Aterro do Flamengo, a Enseada de Botafogo, a Praia de Copacabana e o Complexo do Corcovado, recentemente reconhecido como uma das Sete Maravilhas do mundo e um dos principais atrativos turísticos da cidade.

Este Complexo, localizado no maciço Tijuca, no interior do Parque Nacional da Tijuca (PNT), envolve uma vasta gama de atrativos naturais e culturais. Dentre os principais atrativos, o que mais se destaca é o monumento do Cristo Redentor ${ }^{2}$, um dos principais cartões postais da "Cidade Maravilhosa" e símbolo identitário também para os seus habitantes.

A estátua do Cristo Redentor de braços abertos é também uma das imagens mais utilizadas no marketing turístico internacional sobre o Brasil. Em 2005, o mesmo foi tombado pelo Instituto de Patrimônio Histórico Nacional (IPHAN), o que reforça a sua importância como patrimônio histórico-cultural, em âmbito nacional. E em 2007, o monumento foi eleito uma das novas Sete Maravilhas do Mundo Moderno ${ }^{3}$. O concurso que o elegeu teve grande repercussão na mídia, em nível mundial, uma vez que resultou de uma seleção que envolveu cerca de 100 milhões de votos, e teve forte apelo popular. Segundo os organizadores desta iniciativa, esta vitória ilustrou os sentimentos de orgulho e entusiasmo pela cultura carioca e o monumento que a representa, simbolicamente ${ }^{4}$. Este título rendeu ainda maior visibilidade ao atrativo, bem como incentivou o aumento do número de visitantes brasileiros e estrangeiros. Atualmente, a estátua do Cristo Redentor recebe uma média de $1.400 .000^{5}$ visitantes por ano, se configurando como um dos pontos turísticos mais importantes da cidade e do país.

Mas o monumento do Cristo Redentor não representa um atrativo isolado da cidade, uma vez que integra o Complexo do Corcovado, em conjunto com o mirante do morro do Corcovado, o trem do Corcovado, o hotel das Paineiras (em revitalização) e o próprio Parque Nacional da Tijuca, uma das áreas protegidas de maior visibilidade da cidade do Rio de Janeiro e também do país. A visitação ao Complexo permite também uma vista panorâmica da cidade, que envolve o morro do Pão de Açúcar, o estádio do Maracanã, as várias praias, bairros e favelas das zonas sul, norte e central e, demais atrativos turísticos associados à "Cidade Maravilhosa". 
Diante da relevância simbólica deste atrativo turístico como ícone do processo de reconhecimento da cidade como "Paisagem Cultural da Humanidade" pela UNES$\mathrm{CO}$, de sua importância na rediscussão em planejamento turístico e ecoturístico, em particular (em função do resgate da relação natureza e cultura na perspectiva de planejamento ecoturístico em parques nacionais) e da estimativa de crescimento esperado do número de turistas na cidade, o objetivo deste trabalho é contribuir para interpretar como se expressa e se consolida o imaginário dos turistas que visitam o Complexo do Corcovado, tendo como foco as suas motivações, as impressões sobre a visita e os significados atribuídos à experiência.

Com este objetivo, o trabalho se orientou pelas seguintes questões: Qual é o imaginário desse turista e as suas reais motivações para buscar o Complexo do Corcovado? Quais são as impressões provocadas pela experiência da visita? O imaginário deste turista é re-significado após essa vivência? Que recomendações são explicitadas para a melhoria da experiência no Corcovado?

\section{Caminho Metodológico da Pesquisa}

A presente pesquisa foi desenvolvida com base em abordagem predominantemente qualitativa e foi estruturada em cinco etapas metodológicas: a) pesquisa bibliográfica e documental para a contextualização do Complexo do Corcovado no âmbito do turismo do Rio de Janeiro, e sobre o tema do imaginário em turismo, elemento teórico inspirador do trabalho; b) planejamento de pesquisa de campo, a partir do planejamento logístico e acordos institucionais e da elaboração do instrumento de pesquisa destinado aos turistas domésticos e estrangeiros, que consistiu em questionário (em português e inglês) estruturado em blocos de questões relativas ao perfil do turista, suas motivações, impressões, significados e recomendações para a melhoria da experiência no Corcovado. Nesta etapa foi realizada também a seleção e capacitação dos pesquisadores de campo; c) resgate de pesquisa de campo, propriamente dita, realizada no Complexo do Corcovado, entre agosto e outubro de 2007, portanto na baixa estação. Os questionários foram aplicados de forma aleatória na Estação do Alto do Corcovado, ao final da visita ao monumento do Cristo Redentor, com o apoio da ESFECO (Estrada de Ferro Corcovado) ${ }^{6}$. Foram aplicados no período 757 questionários - 496 dirigidos aos turistas domésticos e 261 aos turistas estrangeiros ${ }^{7}$; d) sistematização estatística preliminar das informações obtidas ${ }^{8}$ para orientar a análise qualitativa, com base em três temas centrais: as motivações do turista para a visita, suas impressões e os significados atribuídos à experiência; e) análise das informações obtidas, tendo como base a Análise de Conteúdo (BARDIN, 1979) a partir dos temas mencionados.

\section{O Complexo do Corcovado: foco da pesquisa}

Diante da importância do Complexo do Corcovado para a cidade do Rio de Janeiro, se objetiva em um primeiro momento contextualizar este atrativo e o processo de uso turístico, que o transformou em símbolo do Rio de Janeiro como ponto de par- 
tida para a presente pesquisa. Mas não se pode ignorar que o Complexo do Corcovado situa-se no Parque Nacional da Tijuca, um dos principais parques urbanos do mundo e importante atrativo para o ecoturismo nacional e internacional.

O Parque Nacional da Tijuca foi criado em 1961 e está localizado na cidade do Rio de Janeiro (RJ), na região sudeste do Brasil. Sua área abrange a parte média superior do Maciço da Tijuca e, em sua inserção na malha urbana da cidade do Rio de Janeiro, estabelece fronteiras com 22 bairros do município. Possui, atualmente, uma área total de 3.953 ha sendo considerado o menor parque nacional brasileiro. A criação do parque incorporou as florestas da Tijuca, Paineiras, Corcovado, Gávea Pequena, Trapicheiros, Andaraí, Três Rios e Covanca, então áreas de florestas públicas administradas pela União (ICMBio, 2008) e esta área protegida é reconhecida, atualmente, como importante testemunho do bioma Mata Atlântica em áreas urbanas.

No entanto é importante assinalar que muito antes de sua criação, desde o século XVI, o morro do Corcovado é reconhecido como um dos principais elementos naturais de referência para os próprios moradores da cidade do Rio de Janeiro. Mas foi apenas no século XVII, que D. Pedro I ${ }^{9}$ (1798-1834) inaugurou, neste local, o mirante do Corcovado, e este despertou, na população da cidade, o desejo de conhecimento do lugar para a prática de atividades de lazer e de turismo. Posteriormente, D. Pedro II $^{10}$ (1825-1891) decidiu reflorestar áreas devastadas do Corcovado visando preservar mananciais de água que abasteciam a cidade, impulsionando o turismo no local (SEMENOVITCH, 1997). E, a partir do momento em que a visita ao morro do Corcovado ganhou importância como oportunidade de lazer, descanso e contemplação da paisagem, o local passou então a receber investimentos em equipamentos e infraestrutura, se consolidando assim como um atrativo turístico de importância nacional (GHETTI; MOREIRA, 2007).

Nesse percurso, a primeira melhoria de acesso à área foi a construção da Estrada de Ferro do Corcovado (1884), que contribuiu significativamente para reforçar o significado turístico do lugar. E mais do que uma linha férrea de acesso, Semenovitch (1997) aponta a importância dessa estrada de ferro para a própria história do Brasil, uma vez que foi essa a primeira ferrovia brasileira exclusivamente turística. Após a sua eletrificação e, consequentemente a redução do valor das passagens e do tempo da viagem para acesso ao local, houve um aumento progressivo no número de visitantes ao Complexo. Além disso, Fraga (2003) afirma que uma parcela significativa de visitantes que optam pela estrada férrea para acesso ao morro do Corcovado, considera o próprio trem de acesso ao monumento como um atrativo turístico, o que o torna um adicional no cenário turístico do lugar. Um outro atrativo turístico neste cenário é também o hotel das Paineiras, inaugurado em 1884, e construído com o objetivo de elevar o nível da hotelaria carioca aos padrões internacionais ${ }^{11}$.

Mas a construção do monumento do Cristo Redentor, atualmente o principal atrativo do Complexo do Corcovado, foi iniciada somente em 1922. A estátua, inaugurada em 12 de outubro de $1931^{12}$, está situada no topo do morro do Corcovado, possui 30 metros de altura e 08 metros de pedestal. Construída em concreto armado e 
revestida em pedra sabão, constitui o elemento central da paisagem, que pode ser vislumbrado de diversos ângulos da cidade, e consolida o Complexo como principal ponto turístico da cidade do Rio de Janeiro (LINHARES; DAPIEVE; MENEZES, 2001).

Para facilitar o acesso ao Cristo Redentor, em 1936 foi construída a estrada rodoviária das Paineiras, ligando os bairros de Cosme Velho e Santa Tereza, ao monumento, o que potencializou o aumento no número de visitantes ao Complexo do Corcovado (GHETTI, MARQUES; MOREIRA, 2006). Na continuidade do processo histórico de constituição do Complexo do Corcovado, em 1961, na área circundante ao monumento do Cristo Redentor, foi criado o Parque Nacional da Tijuca (PNT), uma Unidade de Conservação federal de proteção integral ${ }^{13}$ de quase quatro mil hectares. Esse parque foi criado com os objetivos de prover parte do abastecimento de água da cidade (já que esta área abriga diversas nascentes); prevenir a erosão das encostas; contribuir para a redução da poluição atmosférica; propiciar recreação e melhor qualidade de vida aos habitantes da cidade; além de preservar a paisagem para fomentar o turismo. Assim, o Complexo do Corcovado está associado a um rico patrimônio de importância natural e cultural e importante atrativo ecoturístico da própria cidade.

Com este reconhecimento e, em consequência do movimento de valorização do Complexo como principal ponto turístico do Rio de Janeiro, no ano 2000, foi iniciado o primeiro projeto para a sua modernização, o Projeto Cristo Redentor. Esse projeto teve como objetivo a implantação de elevadores, de uma plataforma metálica, de escadas rolantes, e de nova iluminação e sinalização turística (GHETTI; MOREIRA, 2007). O projeto impulsionou o desenvolvimento do turismo no local, aumentou a visibilidade do Complexo na mídia, e intensificou a sua importância no imaginário coletivo. Como resultado desse processo, em 2005, o monumento do Cristo Redentor foi tombado pelo Instituto do Patrimônio Histórico e Artístico Nacional (IPHAN), recebendo proteção oficial e reconhecimento como patrimônio cultural, de valor nacional. Mais recentemente, em 2010, a estátua do Cristo Redentor foi restaurada e ganhou nova iluminação o que ampliou a visibilidade do Complexo para o Turismo.

Mas mesmo considerando esta trajetória de valorização do Complexo do Corcovado e as ações para a sua modernização, não se conhece, com clareza, como os turistas que o visitam apreendem a experiência no local. Por esta razão, interpretar este imaginário e o significado da experiência constitui a busca desta pesquisa, no sentido de contribuir para um olhar inovador em planejamento turístico.

\section{Compreendendo a noção de imaginário em turismo}

Com o objetivo mencionado, a pesquisa parte do referencial teórico construído a partir de Gastal (2005). A autora discute que o imaginário é formatado a partir de um observador, que o organiza segundo um determinado ponto de vista, em um determinado tempo e espaço particular. O imaginário representa a simplificação de várias associações e informações ligadas ao lugar, resultantes de uma opinião pessoal. É, por- 
tanto, constituído por sentimentos pré-estabelecidos, alimentados por diversas redes de informações, em relação aos locais e atrativos turísticos. Kotler (apud GASTAL, 2005) discute ainda que o imaginário sobre um determinado lugar sintetiza crenças, ideias e impressões sobre ele.

Assim, a partir do momento em que se configura o imaginário sobre determinado objeto, o sujeito dá sentido a partir de suas ideias. "Para criar significado, entretanto, ele (sujeito) põe em atividade uma função da mente - a imaginação" (PITTA, 2005, p.11). Nesse sentido, Bachelard (apud PITTA, 2005) afirma que a organização do mundo não é resultado de uma série de raciocínios, mas sim uma elaboração mental que considera afetos e emoções. Maffesoli (apud GASTAL, 2005) discute ainda que os imaginários estão sempre vinculados a um determinado grupo social, funcionando como um cimento social e traduzindo o estado de espírito do mesmo, em seu próprio contexto ou no contexto de um país.

No que se refere ao turismo, estudos recentes destacam que, cada vez mais, o que os turistas mais "consomem" não são propriamente lugares, produtos e serviços mas os significados a eles agregados, e, portanto, o imaginário a eles associado. Dessa forma, o turismo não se configura apenas a partir de produtos concretos, mas de imaginários, em permanente transformação. A autora discute ainda que produzir e consumir imaginários passou a fazer parte das necessidades básicas humanas. $\mathrm{E}$, neste caso, o imaginário construído sobre um determinado local pode re-significá-lo para além do sentido concreto do próprio lugar turístico.

Assim, a compreensão sobre o imaginário, traduzido em sentimentos, desejos e necessidades humanas tende a ser um conhecimento essencial para o planejamento e a promoção das localidades turísticas e para a sua tradução em políticas públicas e ações governamentais.

É importante enfatizar que, no caso específico desta pesquisa, na cidade do Rio de Janeiro, um dos principais símbolos vinculados ao imaginário da "Cidade Maravilhosa", é o próprio Cristo Redentor. Ghetti, Marques e Moreira (2006) discutem que o imaginário a ele associado é carregado de "valores afetivos e simbólicos", como a seguir ilustrado:

Como um símbolo, representa a integração de um aspecto vivenciado (o sentido) e de um componente espacial (a imagem). Transforma-se assim numa ponte entre a realidade psíquica (do visitante) e a realidade física (do lugar). Neste caso, traduz para o visitante a compreensão de uma realidade - a do caráter singular deste monumento e do caráter sensível do lugar que o abriga (GHETTI, MARQUES; MOREIRA op.cit, 2006, p.34).

Nesse sentido, a interpretação do imaginário deste turista que visita o Corcovado agrega o entendimento sobre as suas motivações para a visita, suas impressões e os significados a ela atribuídos, para além do simples deslocamento ao local e a pos- 
Corcovado: reflexões sobre imaginários e impressões dos turistas no Parque Nacional da Tijuca (RJ) no contexto de valorização da cidade pela UNESCO

sibilidade de "contemplação passiva" da paisagem que o monumento oferece. Com base nestes pressupostos, a questão que se pretende responder com este trabalho é como se expressa o imaginário do turista que visita o Corcovado?

\section{O imaginário do turista sobre o Corcovado: entre suas motivações e significa- dos da experiência}

Como anteriormente mencionado, esta pesquisa partiu do pressuposto que o turismo se constitui em um fenômeno social complexo, que envolve o deslocamento voluntário e temporário de indivíduos e/ou grupos de pessoas por motivações que se constroem a partir do imaginário associado a um determinado lugar turístico. Esse imaginário, como previamente discutido, envolve informações e conhecimentos anteriores à viagem, que se traduzem em motivações; e se consolidam (ou não) em impressões que se constroem na própria experiência; e, por fim, nos significados a ela atribuídos que irão consolidar, ou não, as expectativas previamente estabelecidas.

\section{Para contextualizar o perfil dos sujeitos da pesquisa: quem são estes turistas?}

Evidentemente que uma pesquisa desta natureza tem alcance apenas indicativo e reflete um determinado tempo e perfil. Sendo assim e considerando estas limitações, quem são os turistas pesquisados?

No universo de 496 turistas domésticos pesquisados, a maioria pertence ao sexo feminino $(57,1 \%)$, sendo uma parcela importante situada na faixa etária entre 18 e 49 anos (79\%). Esses turistas são, essencialmente, oriundos das capitais do país, principalmente das regiões sudeste e nordeste $(57 \%)$. O perfil profissional dominante na amostra pesquisada se vincula, principalmente, à condição de profissional liberal e, a maior parcela (42\%) situa-se na faixa de renda familiar entre 05 e 11 salários mínimos $^{14}$, permanecendo na cidade entre 03 e 07 dias $(63 \%)$. A opção por hotéis se destaca em termos de meio de hospedagem selecionado (53\%) por estes turistas e, o principal meio de transporte utilizado, é o aéreo (67\%).

Com relação aos 261 turistas estrangeiros, a amostra pesquisada envolveu um número semelhante de homens e mulheres, com faixa etária predominante entre $18 \mathrm{e}$ 49 anos de idade (58\%). A maioria é também constituída de profissionais liberais (80\%). E do total pesquisado, $40 \%$ possuem renda superior a 14 salários mínimos ${ }^{15}$, permanecendo na cidade, em geral, entre 3 e 7 dias (68\%), se hospedando em hotéis $(82 \%)$ e utilizando, prioritariamente, o transporte aéreo (95\%). Esses são procedentes, predominantemente, da Europa (26\%) e América do Norte (22\%). Mas o que faz estes turistas buscarem o Corcovado como opção em sua estadia na cidade?

\section{Motivações para a visita: o imaginário inspirador}

Embora inúmeras hipóteses tenham sido delineadas para explicar o interesse do turista pelo Corcovado, uma questão parece ainda sem resposta. Quais são os fatores que fazem do Complexo do Corcovado (com destaque para o monumento do 
Cristo Redentor), um dos maiores atrativos turísticos da cidade do Rio de Janeiro? De acordo com a pesquisa, para os turistas domésticos (40\%), o principal fator motivador para a visita ao Corcovado, é o fato deste ser considerado o símbolo do Rio de Janeiro. Este imaginário é reforçado, continuamente, pela mídia e se materializa, frequentemente, nos cartões postais, na divulgação televisiva e em campanhas de turismo, nas quais a imagem do Cristo Redentor é constantemente exibida como representação e marco simbólico da identidade da "cidade maravilhosa". Assim, a visita ao monumento tende a materializar o desejo de contato com a própria cidade.

Mas a vista panorâmica do Cristo Redentor, que pode ser vislumbrada do mirante do Corcovado, é também um fator de motivação para os turistas domésticos (18\%) que visitam o Complexo do Corcovado. Do alto de seus 710 metros de altitude, o turista espera apreciar a exuberante paisagem natural da cidade, que envolve praias, formações rochosas, montanhas, florestas, baía, lagoa, oceano Atlântico, além das grandiosas obras arquitetônicas também visualizadas desse ponto.

Além disso, 15\% dos turistas domésticos têm como principal motivação à visita ao Corcovado, simplesmente o desejo de conhecê-lo. Para alguns, inclusive, a experiência de apreciar a estátua do Cristo tende a significar o "encontro com a cidade" e a "realização de um sonho". E, também sob esta perspectiva o monumento se delineia, no imaginário desses turistas, como símbolo da "Cidade Maravilhosa", já que é por meio do "encontro" com a estátua do Cristo Redentor que o turista realmente tem a impressão de "vivenciar" a cidade, em sua forma mais plena, em termos de escala. Esse sentimento é, evidentemente reforçado, pela mídia televisiva nacional, que não apenas veicula a estátua como patrimônio cultural, mas também como modo de vida carioca. E assim, o "encontro com o Cristo Redentor" potencializa o acesso a um determinado "jeito de ser", conforme discutido por Irving, Corrêa e Moraes (2011) o que realimenta e fortalece o seu impacto no imaginário sobre a cidade.

E o turista estrangeiro, qual a sua motivação para a visita? Assim como o turista doméstico, os turistas estrangeiros que chegam ao Corcovado têm como principal motivação para a visita ao Complexo, o fato do Cristo Redentor ser considerado o símbolo da cidade do Rio de Janeiro (42\%). Para eles, o monumento do Cristo Redentor representa ainda mais do que o símbolo da cidade, o "símbolo do país". Este imaginário fortalece, também internacionalmente, a percepção em relação a este ponto turístico, como uma representação simbólica do encontro do turista com a "Cidade Maravilhosa" e desta, com o próprio país, conforme discutido por Irving, Corrêa e Moraes (2011).

Outro fator motivacional para grande parte dos turistas estrangeiros (26\%) é o fato de o Cristo Redentor ter sido eleito uma das Sete Maravilhas do Mundo Moderno, o que reforça a importância do monumento no imaginário desse turista. Nesse sentido, é possível afirmar que esse título conferido à estátua representou um fator importante para a sua maior visibilidade internacional e, portanto, elemento motivacional de grande relevância para o turista estrangeiro. Ao visitar o monumento, este tem a impressão de estar integrado à cidade e também ao país. Também neste caso, a impor- 
tância do Cristo transcende o seu valor como patrimônio material, uma vez que se consolida no plano simbólico.

Mas para além deste significado, a oportunidade de apreciação da vista panorâmica da cidade também é lembrada pelos estrangeiros (22\%) como fonte motivadora da visita. Para esses, a possibilidade de contemplação das belezas naturais e arquitetônicas da cidade, em uma perspectiva panorâmica, representa uma fonte de interesse especial que justifica a priorização de visita ao local e sua escolha durante o tempo de estadia no Rio de Janeiro.

O turista estrangeiro é também incentivado a conhecer o Complexo do Corcovado por recomendação de amigos. Desta forma não apenas a mídia representa um canal de divulgação internacional do monumento, mas os próprios turistas são importantes meios de difusão do complexo. Sendo assim, a qualidade da experiência vivenciada na cidade tende a ter também um efeito importante na divulgação do atrativo.

Assim, com base no entendimento de que o imaginário é constituído pelas motivações criadas a partir dos sentimentos, desejos e necessidades dos turistas (GASTAL, 2005), pode-se inferir que a atração do Complexo do Corcovado para estes estrangeiros se justifica, principalmente pelo fato de a estátua do Cristo Redentor ser o "símbolo" da cidade do Rio de Janeiro e do país e pela experiência que tende a proporcionar pela perspectiva panorâmica de observação da cidade e da natureza exuberante circundante.

\section{Impressões na experiência vivenciada}

Mas a partir deste imaginário, como são expressas as impressões destes turistas acerca da experiência vivenciada no Corcovado? Quais os motivos de satisfação e frustração na experiência vivenciada? Quais as recomendações desses turistas para o aprimoramento dessa experiência?

Para o turista doméstico, a principal menção de satisfação associada à experiência no Corcovado diz respeito à possibilidade de integração à cidade por meio da vista panorâmica, como anteriormente discutido. Assim, esta perspectiva de contato com a cidade tende a representar mais do que uma simples experiência visual. Essa impressão foi enfatizada por $65 \%$ desses turistas pesquisados. Desta forma, a experiência da paisagem singular da cidade em sua dimensão concreta e simbólica é considerada a principal fonte de encantamento na visita, principalmente por esta integrar natureza e patrimônio cultural. A vista panorâmica possibilita ao observador apreciar a natureza preservada, marcada pela exuberância da mata atlântica, associada aos contrastes urbanos da cidade, em uma dimensão dinâmica e não convencional.

Além do impacto da paisagem, a magnitude da estátua do Cristo Redentor é percebida como fonte de satisfação para $18 \%$ dos turistas nacionais durante a experiência. Desta forma, se a estátua como vínculo com a cidade representou a principal motivação para a visita ao Complexo do Corcovado, após a experiência vivenciada, o impacto da vista panorâmica que integra natureza e cultura tende a ser o principal fa- 
tor para a satisfação dos turistas e, certamente, permanecerá como impressão marcante após seu retorno ao local de origem.

Ainda assim, a possibilidade de observação da floresta e o contato com a natureza também influenciam, positivamente, a visita (5\%). No entanto, ironicamente, apenas $35 \%$ dos turistas domésticos pesquisados têm conhecimento de que o Complexo do Corcovado está localizado no interior de um parque nacional. Mesmo com placas informativas no local e toda a divulgação na mídia sobre este ponto turístico, a grande maioria dos turistas desconhece que uma das "Sete Maravilhas do Mundo" está localizada em uma Unidade de Conservação de proteção integral e, portanto, não está atenta ao seu valor como patrimônio natural coletivo.

A capela, de culto da igreja católica, localizada na base da estátua do Cristo, é também lembrada por $4 \%$ dos turistas nacionais como fator de destaque na visita. $\mathrm{E} o$ sentido religioso, mas também cosmopolita deste monumento, que viabiliza o contato entre turistas de diversos países e a integração de diversas culturas, também gera uma impressão positivada da visita.

Contudo, a experiência no Complexo do Corcovado é vivenciada de forma também afetiva pelos turistas domésticos que traduzem a sua vivência em sentimentos e sensações. Para ilustrar estes sentimentos e percepções, os turistas domésticos utilizam expressões como "sensação de paz", "encanto", "alegria da família" e "possibilidade de compartilhamento de bons momentos com os amigos" para caracterizar o sentido deste momento.

Com relação aos visitantes estrangeiros, da mesma forma que para os turistas domésticos, a vista panorâmica da cidade foi destacada como o principal ponto positivo da visita (65\%). E, após a experiência no Complexo do Corcovado, a magnitude da estátua do Cristo Redentor é também mencionada como impactante (23\%) e elemento marcante da experiência.

A exuberância da natureza é também mencionada por $6 \%$ dos turistas estrangeiros como diferencial da visita, mas a grande maioria destes turistas (73\%), como verificado com os turistas domésticos, desconhece o fato de o Complexo estar inserido no PNT. Apesar de ambos os grupos citarem o contato com a natureza como diferencial da visita, tanto os brasileiros quanto os estrangeiros (e, quase na mesma proporção, 65\%), não conhecem as normas de conduta neste Complexo, que é também um parque nacional, uma vez que não tiveram acesso a este tipo de informação.

A capela é também reconhecida por $4 \%$ dos turistas estrangeiros como ponto de destaque na experiência. $\mathrm{E}$ assim como os turistas brasileiros, os estrangeiros também a associam a um sentimento de "paz" como o grande diferencial da visita.

Partindo-se do pressuposto que toda experiência representa uma síntese das diversas impressões vivenciadas e que estas podem ser positiva ou negativamente significadas, é fundamental que se interprete também os desconfortos e/ou eventuais insatisfações no processo. E com relação a este item, em particular, os turistas domésticos ressaltam a dificuldade de acesso e o trânsito congestionado e a má quali- 
dade do transporte público como entraves para uma experiência de qualidade no Corcovado. Neste caso, a percepção sobre a infraestrutura local e a logística de acesso problemática parece influenciar negativamente a impressão do turista sobre este ponto turístico. Assim, uma infraestrutura de melhor qualidade para a recepção dos visitantes tende a ser essencial para que possíveis desconfortos não afetem, negativamente, a experiência no Corcovado.

Sobre a infraestrutura no Complexo e as condições da visita, foram recorrentes os registros de insatisfação dos turistas domésticos com relação ao alto preço dos ingressos do trem de acesso ao Cristo Redentor (24\%). Além disso, o tempo de espera nas filas (19\%), a grande quantidade de pessoas, simultaneamente, no mirante do Corcovado (18\%), a precária qualidade dos serviços oferecidos pelos bares e restaurantes do local e a falta de limpeza dos sanitários foram citados como problemas identificados na visita. Essas impressões que comprometem o sentido da experiência reforçam a necessidade de investimento, por parte da gestão pública, em serviços de qualidade para atendimento à demanda turística e, consequentemente, para a minimização de frustrações decorrentes da visita.

Ironicamente, e sem que se possa exercer qualquer controle a este respeito, as condições meteorológicas influenciam também, negativamente, a experiência turística no Complexo quando as expectativas de céu claro e sol não são atendidas. Parece haver a expectativa permanente, no imaginário do turista doméstico, de sol e clima quente durante toda a sua estadia na cidade, conforme discutido por Irving, Corrêa e Moraes (2011). Nesse sentido, a névoa persistente, o vento e a chuva na época da pesquisa são motivos de frustração e, consequentemente, geram uma impressão negativa no turista sobre a visita ${ }^{16}$.

Além desses, o fato de alguns turistas "não estarem com a família" também é percebido como um problema, uma vez que a visita ao Complexo do Corcovado, em alguns casos, representa, para além de uma experiência turística, um "momento especial para ser compartilhado com pessoas queridas". O sentido de compartilhamento que a visita inspira raramente é discutido nas estratégias de planejamento do turismo no Parque, mas pode ser um diferencial importante na visita e orientam uma outra lógica de recepção do turista, no futuro.

Em relação às impressões de desconforto dos turistas estrangeiros, esses ressaltam que o excesso de pessoas no local é o principal motivo de insatisfação na experiência (45\%). Além disso, o tempo de espera nas filas do trem $(25 \%)$ e o alto preço do ingresso (7\%) são também mencionados como incômodos na visita. A falta de limpeza do local, a dificuldade de acesso à estátua do Cristo Redentor e os serviços de baixa qualidade dos estabelecimentos de alimentos e bebidas, são ainda mencionados como pontos negativos na experiência (7\%). Esses turistas citam também o fato da capela não estar permanentemente aberta à visitação como motivo de frustração.

A partir destas impressões negativas da visita, algumas recomendações são 
propostas para que seja aperfeiçoada a experiência vivenciada. Os turistas domésticos (13\%) apontam a necessidade de disponibilização de vídeos informativos sobre o local, anteriormente à visita e de guias especializados para acompanhálos no percurso. E o controle do número de visitantes ao Complexo é também uma solicitação recorrente (12\%), com o objetivo de que seja evitado acúmulo de pessoas no local.

No caso dos turistas estrangeiros, o controle de acesso de turistas (14\%) e melhorias no transporte ferroviário $(7 \%)$ são as principais sugestões registradas. Com relação ao controle do acesso de turistas ao Complexo, é mencionada ainda a necessidade da redução do número de turistas, simultaneamente no local para minimizar o desconforto proporcionado pela concentração de turistas no alto do Corcovado para observação da estátua, certamente um motivo de frustração na visita. $E$, com relação às melhorias no transporte, estes enfatizam a necessidade de redução do preço da passagem e do tempo de espera do trem.

Assim, a infraestrutura local, associada à má qualidade e aos preços elevados dos serviços é identificada, por ambos os grupos da pesquisa, como problemas que afetam, negativamente, a experiência no Complexo do Corcovado e para os quais são necessárias melhorias. Mas apesar desses problemas reconhecidos, a visita ao Complexo é avaliada como positiva por $60 \%$ dos turistas domésticos e por $45 \%$ dos turistas estrangeiros, que a consideram "suficientemente boa". E apesar dos problemas, $11 \%$ dos turistas domésticos e $2 \%$ dos turistas estrangeiros pesquisados avaliam que a experiência superou, positivamente, as suas expectativas. E neste caso, o Complexo do Corcovado parece permanecer, na percepção dos turistas como um dos principais pontos turísticos da "Cidade Maravilhosa" que merece a sua escolha.

\section{Após a experiência, o imaginário sobre o Corcovado é resignificado?}

Conforme discutido anteriormente, os turistas domésticos e estrangeiros que visitam o Complexo do Corcovado ali chegam com expectativas a partir dos imaginários sobre este ponto turístico que também integra a percepção sobre a cidade. E a partir de sua vivência, estes tendem a resignificar o local por via de impressões e sentidos captados e internalizados. Mas com essas impressões muitas vezes contraditórias, qual o significado atribuído a esse ponto turístico após a visita? O imaginário sobre o Corcovado é consolidado ao final da visita?

A pesquisa tende a indicar que, tanto para os turistas domésticos como para os estrangeiros, o imaginário anterior à visita, está fortemente atrelado ao monumento do Cristo Redentor, entendido como "símbolo da cidade". E pode-se mesmo afirmar que este imaginário é consolidado após a vivência no Complexo, uma vez que o "encontro" com a estátua do Cristo Redentor permanece como elemento impactante da experiência. Além disso, a estátua, considerada "orgulho do país", 
"maior ponto turístico do Brasil" e até mesmo o "símbolo da América Latina", e também é interpretada em seu significado simbólico e imaterial.

Mas após a experiência, o impacto da vista panorâmica inicialmente não considerada como a principal fonte de motivação para a visita, emerge como um dos principais significados do Complexo, para a grande maioria dos turistas, tanto domésticos como estrangeiros. Assim, ao que tudo indica, a experiência vivenciada contribui para a re-significação do Complexo transcendendo o contato com a própria estátua como símbolo da cidade para considerar também a grandiosidade da vista panorâmica.

Assim como a vista panorâmica após a experiência, o sentido de religiosidade associado à visita ao Complexo passa a compor o significado do Corcovado para alguns turistas. E também neste caso, o imaginário sobre o Complexo parece também ser re-significado. Mas como mencionado, a riqueza do patrimônio natural do Parque Nacional da Tijuca impressiona e agrega um importante valor ao significado atribuído à visita, mesmo quando se considera que poucos têm conhecimento do Corcovado como elemento de patrimônio cultural de uma área protegida, de elevado valor ecológico expresso pelo bioma Mata Atlântica.

Outro fator relevante para os estrangeiros na visita se refere ao Complexo como símbolo de contato com a "cultura brasileira". Assim o fato destes terem vivenciado essa "aproximação", seja por meio da vista panorâmica da cidade, ou pelo encontro entre cidadãos de todo o mundo é também elemento impactante na apreensão simbólica do lugar.

E diante desta experiência complexa e pulsante, o turista acaba por consolidar um imaginário positivo sobre a experiência no Complexo do Corcovado, marcado predominantemente pela simbologia envolvida neste ponto turístico. Essa simbologia se traduz, para os turistas domésticos e estrangeiros, em sentimentos de "paz", "harmonia", "amor", "felicidade" e "liberdade" e na percepção da indissociabilidade entre natureza e cultura.

\section{Considerações Finais}

Esta pesquisa, embora exploratória, parece ilustrar, pedagogicamente, no caso do Complexo do Corcovado, o sentido de "Paisagem Cultural da Humanidade" atribuído ao Rio de Janeiro pela UNESCO. O sentido de paisagem, neste caso, reafirmado como a intermediação entre o físico e o fenômeno, entre a ecologia e o simbólico, entre o factual e o sensível (BERQUE, 1995).

A interpretação da experiência vivenciada no Complexo em suas interfaces claras entre natureza e cultura parece também imprimir um novo sentido ao Parque Nacional da Tijuca, para além de seus atributos ecológicos, o que certamente 
tende a implicar em uma nova perspectiva em planejamento (eco) turístico, no caso de áreas protegidas urbanas.

Mas é fundamental que se considere o desconhecimento generalizado sobre a inserção do Corcovado no Parque Nacional da Tijuca como um alerta em planejamento, no âmbito das políticas públicas de proteção da natureza e também de turismo. Considerando o impacto do Corcovado no imaginário do turista que visita o Rio de Janeiro e o seu valor simbólico na associação direta entre natureza e cultura no ambiente urbano de uma das maiores capitais do país, parece inadmissível que o Instituto Chico Mendes de Biodiversidade não tenha ainda desenvolvido uma estratégia de planejamento turístico que integre na visita ao Corcovado, a valorização do sentido de conservação da biodiversidade e a difusão da importância ecológica do Parque Nacional da Tijuca, com base no reconhecimento do valor afetivo e subjetivo do próprio Corcovado. Por outro lado, é interessante que as políticas de turismo não tenham ainda sido capazes de associar, de maneira efetiva, no marketing turístico da cidade, o Parque Nacional da Tijuca ao próprio Corcovado. Assim, em geral, no marketing turístico, o Corcovado é divulgado como "atrativo cultural" e o Parque Nacional da Tijuca, como "atrativo natural" da cidade, reforçando uma cisão entre natureza e cultura, no sentido contrário do processo de reconhecimento de paisagem cultural pela UNESCO. Mas talvez o título recente atribuído à cidade passe a funcionar como "inspiração" para o delineamento de uma nova filosofia de planejamento em políticas públicas, que se desdobre em estratégias mais efetivas de inovação em turismo, com base na afirmação da leitura do turismo como fenômeno social complexo e que, portanto não pode prescindir da interpretação das subjetividades envolvidas como ilustram, preliminarmente, os resultados deste trabalho.

Neste sentido, a pesquisa tende a confirmar que, no imaginário de brasileiros e estrangeiros, o Complexo do Corcovado, com destaque para a estátua do Cristo Redentor, se reafirma por seu valor que transcende o sentido de um atrativo cultural situado em um parque nacional para se expressar como símbolo da cidade do Rio de Janeiro. De braços abertos, o Cristo Redentor representa assim uma "maravilha" que o turista que chega à cidade deseja conhecer. E ao visitar este monumento e todo o Complexo, este tende a buscar, de alguma maneira, a materialização de suas expectativas sobre a cidade, a partir do imaginário construído sobre o lugar.

\section{Referências bibliográficas}

ALMEIDA, L.F.; LODI, M.C. Paisagens Cariocas: Desenvolvimento sustentável, cultura e natureza na cidade. Cadernos FGV Projetos, Junho/Julho, ano 7, №20, pag 7885, 2012.

BARDIN, L. Análise de Conteúdo. Lisboa: Edições 70, 1979. 
BERQUE, A. Lês raisons de paysage de La Chine antique aux environnemements de de synthèse, Hazan: Paris, 1995.

FRAGA, C. C. L. Trem do Corcovado. Experiência funcional ou turística? Monografia apresentada ao Curso de Bacharelado em Turismo pela Universidade Federal de Juiz de Fora, 2003.

GAGNON, G. Le wilderness et le paysage comme fonde des príncipes environnementaux Du monde occidental contemporain. L'exemple des aires protegées américaines et françaises. Mémoire presentée à la Faculté des Études Superieures de I'Université de Laval dans le cadre du programme de maîtrise en Philisophie pour I'obtention du grade de Maitre des Arts. Québec: Faculté de Philisop'hie, Université de Laval, 2005.

GASTAL, S. Turismo, imagens e imaginários. São Paulo: Aleph, 2005.

GHETTI, N.C.; MARQUES, A. S., MOREIRA, A. Mirante do Corcovado: significados e mudanças espaciais na busca da sustentabilidade e da preservação deste patrimônio. Anais do I Fórum Nacional de Conselhos de Patrimônio Cultural. Itajaí, 2006.

GHETTI, N.C.; MOREIRA, A,. Complexo do Corcovado: Significados, Mudanças Espaciais e Lazer. VIII Seminário Lazer em Debate. Rio de Janeiro, p. 910-115, 2007.

ICMBio (nstituto Chico Mendes de Conservação da Biodiversidade). Plano de Manejo do Parque Nacional da Tijuca. Rio de Janeiro, 2008.

IRVING M. A; CORRÊA F.V.; MORAES E.A. Cidade maravilhosa? Interpretando a percepção do turista sobre o Rio de Janeiro. Caderno Virtual de Turismo, v.11, n. 03, 2011.

LINHARES, Z.; DAPIEVE, A.; MENEZES, P.C. Da janela vê-se o Redentor. Rio de Janeiro: Casa da Palavra, 2001.

SEMENOVITCH, J. S. Corcovado: A Conquista da Montanha de Deus. Rio de Janeiro: Editora Lutercia, 1997.

PITTA, D. P. R. Iniciação à teoria do imaginário de Gilbert Durand. Rio de Janeiro: Atlântica editora, 2005 (coleção filosofia).

\section{Notas \\ ${ }^{1}$ Este evento foi divulgado em 01 de julho de 2012 por toda a mídia impressa e televisiva, mas os documentos finais ainda não estão disponíveis para consulta. \\ ${ }^{2}$ Este monumento, foi construído em 1937 pelo engenheiro Heitor Silva Costa e pelo escultor Paul Landowski. \\ ${ }^{3}$ Cristo Redentor está entre as sete novas maravilhas do mundo e foi eleito dentre muitos outros expressivos concorrentes, tais como a Grande Muralha da China, a cidade de Machu Picchu (Peru), o Coliseu (Itália) e o Taj Mahal (Índia). Disponível em <http:// www.folha.uol.com.br/folha/ilustrada/ult90u310254.shtml> Acessado em 28 de abril 2011.}


${ }^{4}$ Livre tradução dos autores do recorte "Could there be a connection between, on the one hand, the motivation and the pride, enthusiasm and the compassion that people have for their culture and monuments that symbolically represent them, and, on the other, their motivation to make a brighter future for themselves? My response is: Yes, this is definitely the case and ultimately also the reason that cultural identity is so important to every single human being and to all societies on our planet! Disponível em www.new7wonders.com. Acessado em 21 de abril de 2010.

${ }^{5}$ Parque Nacional da Tijuca. Estatística de Visitação - 2009 e 2010.

${ }^{6}$ Instituição responsável pela administração do Trem do Corcovado.

${ }^{7}$ Importante destacar que os questionários foram aplicados no momento de retorno da visita ao Morro do Corcovado, com o objetivo de apreender as impressões do turista após este ter vivenciado a experiência de visita a uma das reconhecidas "maravilhas" contemporâneas.

${ }^{8}$ Para tanto, foi utilizado em um primeiro momento o software SPHINX 4.5, distribuído pela SPHINX Brasil, licenciado para o Laboratório de Tecnologia e Desenvolvimento Social, da COPPE-UFRJ.

${ }^{9}$ Primeiro Imperador do Brasil de 1822 a 1831.

${ }^{10}$ Segundo Imperador do Brasil de 1840 a 1889.

${ }^{11}$ Embora desativado há quase 25 anos (por pendências jurídicas relacionadas à propriedade do estabelecimento entre a Secretaria do Patrimônio da União (SPU) e a Universidade Veiga de Almeida), em 2009, como parte das iniciativas do Instituto Chico Mendes de Biodiversidade (órgão responsável pela gestão da área do Parque Nacional da Tijuca, onde se insere o Complexo do Corcovado) de revitalização da área do complexo Paineiras, foi firmada uma parceria com o Instituto de Arquitetos do Brasil (IAB) e promovido um concurso para escolha do melhor projeto de recuperação desse hotel, atualmente em andamento (para maiores informações sobre o concurso e resultado consultar <http://www.iabri.org.br/concursopaineiras/>).

${ }^{12}$ Atualmente administrado pela Arquidiocese do Rio de Janeiro.

${ }^{13}$ Segundo o SNUC as UCs de Proteção Integral tem como objetivo básico "preservar a natureza, sendo admitido apenas o uso indireto dos seus recursos naturais" (BRASIL, 2000).

${ }^{14}$ Considerando que, à época da pesquisa, o salário mínimo no Brasil era de $\mathrm{R} \$ 380,00$, equivalente a $\$ 201,00$ (dólares).

${ }^{15}$ Considerando o valor nacional do salário mínimo.

${ }^{16}$ Nos dias de aplicação dos questionários as condições climáticas não estavam favoráveis.

\section{Agradecimentos}

Os autores agradecem o apoio recebido em alguns estágios da pesquisa à Edilaine Moraes, Carla Conceição Lana Fraga, Ivan Bursztyn, Graciella Faico, Eunice Mancebo e Rodrigo Fasano. 
Marta de Azevedo Irving: Universidade Federal do Rio de Janeiro, Rio de Janeiro, RJ, Brasil.

Email: marta.irving@mls.com.br

Link para currículo Lattes: http://lattes.cnpq.br/1912229324377473

Frances Vivian Corrêa: Universidade Federal do Rio de Janeiro, Rio de Janeiro, RJ, Brasil.

Email: francesvivian@uol.com.br

Link para currículo Lattes: $\underline{\text { http://lattes.cnpq.br/7590460094647999 }}$

Bruna Ranção Conti: Universidade Federal do Rio de Janeiro, Rio de Janeiro, RJ, Brasil.

Email: bruna-conti@hotmail.com

Link para currículo Lattes: http://lattes.cnpq.br/5130616222632742

Eloise Silveira Botelho: Universidade Federal de Juiz de Fora. Juiz de Fora, MG, Brasil.

Email: eloisebotelho@hotmail.com

Link para currículo Lattes: http://lattes.cnpq.br/2389958939659180

Sônia Lúcia Peixoto : Universidade Federal do Rio de Janeiro, Rio de Janeiro, RJ, Brasil.

Email: soniapeixoto@terra.com.br

Link para currículo Lattes: http://lattes.cnpq.br/4349315362087984

Data de submissão: 25 de julho de 2012

Data de recebimento de correções: 31 de julho de 2012

Data do aceite: 31 de julho de 2012

Avaliado anonimamente 